\title{
A Pilot Study of Diabetes Management in the Managed Care Setting
}

Rachel Wagman

Thomas Jefferson University

Follow this and additional works at: https://jdc.jefferson.edu/tmf

Part of the Endocrinology, Diabetes, and Metabolism Commons Let us know how access to this document benefits you

\section{Recommended Citation}

Wagman, Rachel (2001) "A Pilot Study of Diabetes Management in the Managed Care Setting," The Medicine Forum: Vol. 3 , Article 9.

DOI: https://doi.org/10.29046/TMF.003.004

Available at: https://jdc.jefferson.edu/tmf/vol3/iss1/9

This Article is brought to you for free and open access by the Jefferson Digital Commons. The Jefferson Digital Commons is a service of Thomas Jefferson University's Center for Teaching and Learning (CTL). The Commons is a showcase for Jefferson books and journals, peer-reviewed scholarly publications, unique historical collections from the University archives, and teaching tools. The Jefferson Digital Commons allows researchers and interested readers anywhere in the world to learn about and keep up to date with Jefferson scholarship. This article has been accepted for inclusion in The Medicine Forum by an authorized administrator of the Jefferson Digital Commons. For more information, please contact: JeffersonDigitalCommons@jefferson.edu. 


\title{
A Pilot Study of Diabetes Management in the Managed Care Setting
}

\author{
Rachel Wagman, MD, Resident Department of Internal Medicine 1997-2000 \\ and Michael Steinberg, MD, MPH
}

\section{Introduction}

Diabetes mellitus represents a disease entity that primary care providers commonly encounter in the outpatient setting. Patient visits encompass a broad range of concerns, from optimizing management of hyperglycemia to the sequelae of chronic disease. The third National Health and Nutrition Exam Survey (NHANES III) 1988-1994 has reported the prevalence of diabetes mellitus type 2 in the U.S adult population at $12.3 \%$. The cost of diabetes in 1998 , estimated at $\$ 77$ billion $^{2}$, is a formidable challenge to the health care community and third-party payers. Historically, Health Maintenance Organizations (HMOs) have encouraged more preventative tests, procedures, and exams to curtail the development of chronic disease than indemnity plans ${ }^{3}$. The influx of patients of all ages into these capitated plans has spurred such organizations to reconcile cost-conscious initiatives with the expense of chronic disease using treatment algorithms. Aetna U.S. Healthcare (USHC) has developed Healthy Outlook Programs to manage patients with diabetes using patient education, treatment recommendations, and a U.S. Quality Algorithm (USQA) Diabetes Performance Report for providers ${ }^{4}$. It is not clear whether this program has helped patients with Type 2 diabetes achieve improved glycemic control, receive enhanced screening, and earlier interventions for disease complications compared with indemnity patients. This pilot study seeks to evaluate the effectiveness of managed health care initiatives in improving the quality of care for Type 2 diabetes. In addition, it considers whether differences exist in the care between capitated and indemnity diabetic patients.

\section{Methods}

A five-physician office practice affiliated with a teaching community hospital in suburban Philadelphia served as the site of a retrospective chart review. Patients were identified by billing slips dated from August 1998 through February 1999. A computer audit generated a list of all patients seen August 1999 through February 2000 with the coded diagnosis of diabetes mellitus, ICD-9 250.00. Study participants were defined as having diabetes mellitus type 2 if: 1 ) they exhibited a random blood sugar of $>126 \mathrm{mg} / \mathrm{dL}$ on more than two occasions when seen in the primary care office in the course of one year or 2) they received pharmacologic therapy by chart documentation. Patients were evaluated based on nine services: weight measurement, microalbumin, blood glucose, lipid panel, treatment of dyslipidemia, angiotensin converting enzyme inhibitor use, ophthalmologic, podiatry, and nutritionist referrals. The average weight and blood glucose levels were tabulated. Intervention with lipid-lowering agents and angiotensin converting enzyme inhibitor were noted as present or absent. Referrals to ophthalmology, podiatry, and dietician services were noted as present or absent.

Patients were excluded if they were enrolled in a Preferred Provider Organization (PPO), Medicare, or Medicare $\mathrm{HMO}$; changed insurance in less than one year; history of diabetes mellitus type 1, pancreatitis, glucocorticoid use; or insufficient documentation for diagnosis.

The data was merged with the statistical program, SPSS. Statistical analysis used the student's two-tailed t test to establish differences between the two groups. Statistical significance was noted for a $\mathrm{p}$ value $<0.05$.

\section{Results}

The cohort comprised 18 capitated and 14 indemnity patients, and $\mathrm{N}=$ number of patient visits. Table 1 reflects demographic data of the patients. The average age of capitated patients was 55 years while indemnity patients were 58 years, $\mathrm{p}$ value $=0.057$. Capitated patients weighed on average $223 \mathrm{lb} .+/-57 \mathrm{lb}$. while indemnity patients weighed $185 \mathrm{lb} .+/-52 \mathrm{lb}, \mathrm{p}<0.0001$.

Glycemic control was evaluated based on the number of laboratory draws for each group. The average blood glucose for capitated patients was $181+/-69 \mathrm{mg} / \mathrm{dL}$ while the average blood glucose for indemnity patients was 158 $+/-54 \mathrm{mg} / \mathrm{dL} ; \mathrm{p}$ value $=0.029$.

The management of dyslipidemia between the two groups was noteworthy: although the average total cholesterol of each group was nearly the same, $23 \%$ of indemnity patients versus $46 \%$ of capitated patients were receiving medical 
Table 1. Demographic Data

\begin{tabular}{|l|l|l|l|}
\hline & Capitated & Indemnity & p value \\
\hline Age (yrs) & 55 & 58 & 0.057 \\
\hline Male & 9 & 2 & \\
\hline Female & 9 & 12 & \\
\hline Weight (lb) & 223 & 185 & 0.0001 \\
\hline SD Weight & 47 & 52 & 0.029 \\
\hline $\begin{array}{l}\text { Average } \\
\text { Glucose } \\
(\mathrm{mg} / \mathrm{dL})\end{array}$ & 181 & 157 & \\
\hline $\mathrm{SD}(\mathrm{mg} / \mathrm{dL})$ & 69 & 54 & \\
\hline
\end{tabular}

Table 2. Cholesterol and LDL Data

\begin{tabular}{|c|c|c|c|}
\hline & Capitated & Indemnity & p value \\
\hline \multicolumn{4}{|c|}{ Average Total Cholesterol } \\
\hline$(\mathrm{mg} / \mathrm{dL})$ & 218 & 220 & 0.753 \\
\hline $\mathrm{SD}(\mathrm{mg} / \mathrm{dL})$ & 34 & 44 & \\
\hline \multicolumn{4}{|c|}{ Total Cholesterol Treated } \\
\hline $\mathrm{N}=\#$ pt visits & $32 / 70$ & $21 / 90$ & \\
\hline$\%$ tx'd & $46 \%$ & $23 \%$ & 0.005 \\
\hline \multicolumn{4}{|c|}{ Total Cholesterol at Goal $<200 \mathrm{mg} / \mathrm{dL}$} \\
\hline $\mathrm{N}=\#$ pt visits & $22 / 62$ & $24 / 75$ & \\
\hline$\%$ at goal & $36 \%$ & $32 \%$ & 0.667 \\
\hline \multicolumn{4}{|l|}{ Average LDL } \\
\hline$(\mathrm{mg} / \mathrm{dL})$ & 136 & 145 & 0.142 \\
\hline $\mathrm{SD}(\mathrm{mg} / \mathrm{dL})$ & 31 & 35 & \\
\hline \multicolumn{4}{|c|}{$\mathrm{LDL}$ at Goal $<130 \mathrm{mg} / \mathrm{dL}$} \\
\hline $\mathrm{N}=\#$ pt visits & $22 / 51$ & $26 / 63$ & \\
\hline$\%$ at goal & $46 \%$ & $54 \%$ & 0.841 \\
\hline \multicolumn{4}{|c|}{$\mathrm{LDL}$ at Goal $<100 \mathrm{mg} / \mathrm{dL}$} \\
\hline $\mathrm{N}=\#$ pt visits & $6 / 51$ & $2 / 47$ & \\
\hline$\%$ at goal & $11 \%$ & $4 \%$ & 0.175 \\
\hline
\end{tabular}

treatment $(\mathrm{p}=0.005)$. Despite treatment differences, the data, although not statistically significant, showed a trend that neither group achieved goal cholesterol $<200 \mathrm{mg} / \mathrm{dL}$, $\mathrm{LDL}<130 \mathrm{mg} / \mathrm{dL}$, or $\mathrm{LDL}<$ goal $100 \mathrm{mg} / \mathrm{dL}$.

The utilization of microalbumin testing was low for both groups; $7.2 \%$ of capitated patients versus $6.7 \%$ of indemnity patients were screened; those with positive findings were under treatment with an angiotensin converting enzyme inhibitor. Ophthalmology screening revealed that only $6.7 \%$ indemnity patients were referred as opposed to $20 \%$ of capitated patients, $\mathrm{p}=0.011$. Podiatry and nutrition evaluations revealed a small referral rate and the difference between the two cohorts was not significant (data not shown).

\section{Discussion}

The data reveal that capitated patients tended to be more overweight with inferior glycemic control compared with indemnity patients. This may reflect gender differences: nearly all indemnity participants were women while the capitated patients were equally divided between men and women. Note that the average blood sugar reflects both fasting and random values for each group. The more pronounced hyperglycemia in the capitated group may reflect the higher body mass index and thus, greater insulin resistance. The capitated group fared better in decisions for pharmacologic therapy of dyslipidemia as well as referral to ophthalmology. This may reflect the practitioner's lower threshold to screen and treat patients with an elevated body mass index. However, one would expect this to extend to other services that diabetics seek, including screening for nephropathy and recommendation to other health care providers for a multi-specialty approach to care. Differences were not significant between the groups in screening for nephropathy, use of angiotensin converting enzyme inhibitor, or other subspecialty referrals.

This pilot study had several limitations. The number of patients in each cohort limited meaningful comparisons between the two groups. Chart reviews are contingent on the completeness of the practitioner's notes with treat- 
ment plan and follow-up correspondence from the subspecialist. This evaluation did not include duration of time that the patients were diabetic; newly diagnosed diabetics may not have had the disease of sufficient time to allow for all referrals and interventions to be examined.

Interestingly, ADA guidelines for glycemic and dyslipidemia management have not been strictly followed for either group of patients. Short office visits may limit the types of interventions that can be pursued for diabetes, let alone any comorbidities. A solution may be the use of a mid-level practitioner who could assist in the care in managing these patients. This would allow for follow-up between physician visits to review glycemic control, highlight annual screening measures, and review referral notes from subspecialists. This also could serve as a time to reinforce dietary habits. Such enhancement of contact between health care providers and patients may allow for earlier intervention in the management of complication of diabetes. The publication of improved outcomes of diabetic patients who receive additional health care may provide momentum to include mid-level practitioners in the care of these individuals.

Special thanks to Christine Steinberg, MS for statistics and Matthew Killion, MD for review of the manuscript.

\section{REFERENCES}

1. Harris, Maureen, et al. Prevalence of Diabetes, Impaired Glucose, and Impaired Glucose Tolerance in U.S. Adults. The Third National Health and Nutrition Examination Survey, 1988-1994. Diabetes Care. 21(4); 518-524, 1998

2. American Diabetes Association. Economic Consequences of Diabetes Mellitus in the U.S. in 1997. Diabetes Care. 21(2); 296-309, 1998

3. Quickel, Kenneth E. Diabetes in a Managed Care System. Annals of Internal Medicine. 124(1); 16-163, 1996

4. Aetna-US Healthcare reports obtained from this primary care office records. 